\begin{tabular}{|c|l|}
\hline Title & Deuterium retention of boron-titanium and reduction of deuterium retention after helium ion irradiations \\
\hline Author(s) & Hino, T.; Hashiba, Y.; Y amauchi, Y.; Nishimura, K.; A shikawa, N.; Sagara, A.; Noda, N.; Komori, A .; Motojima, O. \\
\hline Citation & $\begin{array}{l}\text { Fusion Engineering and Design, 85(5), 655-660 } \\
\text { https://doi.org/40.1016/.fusengdes.2010.03.008 }\end{array}$ \\
\hline Issue Date & 2010-08 \\
\hline Doc URL & http://hdl.handle.net/2115/43900 \\
\hline Type & article (author version) \\
\hline File Information & FED85-5_655-660.pdf \\
\hline
\end{tabular}

Instructions for use 


\title{
Deuterium Retention of Boron-titanium and Reduction of Deuterium Retention after Helium Ion Irradiations
}

\author{
T. Hino ${ }^{1,2}$, Y. Hashiba $^{1}$, Y. Yamauchi ${ }^{1}$, K. Nishimura ${ }^{2}$, N. Ashikawa ${ }^{2}$, A. Sagara ${ }^{2}$, \\ N. Noda ${ }^{2}$, A. Komori ${ }^{2}$ and O. Motojima ${ }^{2}$ \\ ${ }^{1}$ Laboratory of Plasma Physics and Engineering, Hokkaido University, \\ Sapporo, 060-8628 Japan \\ ${ }^{2}$ National Institute for Fusion Science, Toki-shi, 509-5202 Japan
}

\begin{abstract}
Deuterium ion irradiations with an ion with energy of $1.7 \mathrm{keV}$ were conducted for boron-titanium (B-Ti) film prepared by electron beam evaporation and hot pressed titanium-boride, $\mathrm{TiB}_{2}$. The amount of retained deuterium was measured for these materials using a technique of thermal desorption spectroscopy. The amount of deuterium retained in $\mathrm{TiB}_{2}$ was comparable with that in B-Ti. Desorption peaks of deuterium in $\mathrm{B}-\mathrm{Ti}$ were 470 and $620 \mathrm{~K}$, corresponding to a desorption in the low temperature regime observed in boron (B) and a desorption in titanium (Ti), respectively. The desorption peaks in $\mathrm{TiB}_{2}$ were $620 \mathrm{~K}$ and $750 \mathrm{~K}$, which correspond to the desorption in $\mathrm{Ti}$ and that in the high temperature regime in $\mathrm{B}$, respectively. The desorption temperature in $\mathrm{B}-\mathrm{Ti}$ was approximately $100 \mathrm{~K}$ lower than that in $\mathrm{TiB}_{2}$. This difference is discussed based upon chemical bindings and crystal structures of $\mathrm{B}-\mathrm{Ti}$ and $\mathrm{TiB}_{2}$. Irradiation of helium ion with energy of $5 \mathrm{keV}$ was conducted for B-Ti after the deuterium ion irradiation. The amount of retained deuterium decreased and the desorption temperature shifted to the lower temperature regime, as the helium ion fluence increased. The shift to the low temperature regime is due to enhancement of amorphous structure of B in B-Ti.
\end{abstract}

Keywords: Boron-titanium, Titanium-boroid, Boron, Titanium, Deuterium retention, Desorption temperature, Crystal structure, Amorphous

\section{Introduction}

Titanium flash and boronization have been often employed for controls of fuel hydrogen recycling and oxygen impurity level in fusion devices. In the titanium flash, titanium is deposited on the first walls by the evaporation using a heater. The titanium well absorbs the hydrogen and then titanium hydride is produced. The hydrogen 
recycling during the plasma discharge is reduced if the hydrogen is retained in the titanium. Since an evaporation energy of hydrogen in the titanium hydride is relatively low [1], a thermal desorption temperature of hydrogen retained in titanium is low. Boronization is occasionally conducted using a glow discharge with a gas containing boron species such as diborane and tri-methyl boron gases [2-4]. Boronized walls well absorb oxygen impurity and thus the oxygen impurity concentration in the plasma is significantly reduced [5, 6]. It is known that desorption temperatures of hydrogen retained in the boron are in the range of 500-800 $\mathrm{K}$ [7], lower than that in graphite, 1000-1100 K [8]. Amount of fuel hydrogen retained in the boron can be reduced by a wall baking with relatively low temperature, compared with the case of graphite. Therefore, the boronized wall with a relatively high baking temperature can contribute to the reduction of fuel hydrogen recycling.

In the case of boronization followed by titanium flash or vice versa, boron-titanium (B-Ti) is produced on the wall. The hydrogen retention behavior may be changed compared with the titanium or the boron. In our previous experiments, the deuterium ion irradiation was conducted for B-Ti prepared by electron beam evaporation, and the deuterium retention and desorption behavior were examined [8]. The amount of retained deuterium was several times lower than that of boron or titanium. In addition, the desorption temperature was lower than those of boron and titanium. The lower desorption temperature observed in B-Ti may be due to the chemical binding states of boron and/or crystal structure of B-Ti. In the present study, the amount of retained hydrogen and desorption temperature are measured for crystallized titanium-boride, i.e. $\mathrm{TiB}_{2}$. Thease are compared with those of $\mathrm{B}-\mathrm{Ti}$, Ti and $\mathrm{B}$ films prepared by electron beam evaporation. In order to understand the deuterium retention and desorption behavior of $\mathrm{B}-\mathrm{Ti}$, the crystal and chemical binding states of $\mathrm{B}-\mathrm{Ti}$ and $\mathrm{TiB}_{2}$ are examined, and the differences in these materials are discussed. In addition, helium ion impact desorption for B-Ti after the deuterium ion irradiation is conducted and the changes of retention and desorption behavior are examined.

\section{Experiments}

Hot pressed boron-titanium, $\mathrm{TiB}_{2}$, (Furuuchi Chemical Ltd.), was employed as the crystallized sample. The sample size of $\mathrm{TiB}_{2}$ was $10 \times 20 \times 5 \mathrm{~mm}$. The samples of B-Ti, $\mathrm{B}$ and Ti films were prepared using electron beam evaporation (EBE). 316L SS plate with a size of $10 \times 70 \times 0.1 \mathrm{~mm}$ was used as the substrate. Boron target with a purity of 99.99 at\% or titanium target was irradiated by electron beams with energy of 4-5 keV. For the preparation of B-Ti, the titanium was deposited with a thickness of $90 \mathrm{~nm}$ on the 
substrate at room temperature (RT), and after that the boron was deposited with a thickness of $10 \mathrm{~nm}$ at RT. The film thickness was monitored using a quartz thickness monitor during the evaporation. The total film thickness was $100 \mathrm{~nm}$. After the evaporation, the sample was annealed for $30 \mathrm{~min}$ at $973 \mathrm{~K}$, in order to mix the titanium and boron contents. The depth profile of atomic composition was examined using Auger electron spectroscopy (AES). Ti and B films on 316L SS were similarly prepared. The thickness of B or Ti film was $100 \mathrm{~nm}$. The annealing treatment for B and Ti samples was not conducted.

The $\mathrm{TiB}_{2}$ sample was irradiated by the deuterium ions with an energy of $1.7 \mathrm{keV}$ and fluences from $1 \times 10^{17}$ to $5 \times 10^{18} \mathrm{D} / \mathrm{cm}^{2}$ at $\mathrm{RT}$ in an ECR ion irradiation device at Hokkaido University [7]. The samples, B-Ti, B and Ti, were irradiated with the fluence of $5 \times 10^{18} \mathrm{D} / \mathrm{cm}^{2}$ at RT. The fluence of $5 \times 10^{18} \mathrm{D} / \mathrm{cm}^{2}$ is sufficiently enough for the amount of retained deuterium to saturate. After the deuterium ion irradiation, the sample was transferred to a chamber of thermal desorption spectroscopy (TDS). The sample temperature was increased from $300 \mathrm{~K}$ to $1000 \mathrm{~K}$ with a heating rate of $30 \mathrm{~K} / \mathrm{min}$. During the heating, a desorption rate of deuterium gas was qualitatively measured using a quadruple mass spectrometer (QMS). The peak temperatures in the desorption rate were observed from the desorption spectrum. The amount of retained deuterium was obtained by integrating the desorption rate with respect to the heating time or temperature.

Thick B-Ti sample with a thickness of $300 \mathrm{~nm}$ was prepared for measurement of $\mathrm{X}$-ray diffraction (XRD). XRD spectra were measured for $\mathrm{B}-\mathrm{Ti}$ and $\mathrm{TiB}_{2}$ in order to examine the crystal structures. X-ray photoelectron spectroscopy (XPS) was conducted for $\mathrm{B}-\mathrm{Ti}$ and $\mathrm{TiB}_{2}$ in order to examine the chemical binding states of $\mathrm{B}$.

\section{Results}

\section{(1) Depth Profiles of Atomic Composition for $\mathrm{TiB}_{2}, \mathrm{~B}-\mathrm{Ti}, \mathrm{B}$ and $\mathrm{Ti}$}

The depth profile of atomic composition of $\mathrm{TiB}_{2}$ is shown in Fig.1. The atomic ratio of $\mathrm{B}$ to $\mathrm{Ti}$ is approximately 2 except the top surface region. The depth profiles of atomic composition in Ti film, B film and B-Ti film before annealing are shown in Figs. 2 (a), (b) and (c), respectively. In the Ti, the carbon and oxygen concentration were observed to be high, 30 at\% and 20 at\%, respectively. These impurities might have been due to the carbon and oxygen contained in the titanium target and/or depositions of residual carbon and oxygen gases in the chamber. In the B, the purity of boron was high, 93 at\%. The B-Ti in Fig. 2(c) has Ti and B layers. Figure 2(d) shows the depth profiles of atomic composition in B-Ti after the annealing at $973 \mathrm{~K}$ for $30 \mathrm{~min}$. After the annealing, 
both titanium and boron diffused and the mixing layer was produced at the surface region. The atomic ratio of $\mathrm{B}$ to Ti was approximately 2 at the surface. An ion projected range of $1.7 \mathrm{keV}$ deuterium is approximately $20 \mathrm{~nm}$, so that the deuterium ion is implanted to the region with $\mathrm{B} / \mathrm{Ti} \sim 2$.

\section{(2) Deuterium Desorption Behavior of B-Ti, B, Ti and $\mathrm{TiB}_{2}$}

The thermal desorption spectra after the deuterium ion irradiation for $\mathrm{B}$, $\mathrm{Ti}$ and $\mathrm{B}$-Ti were shown in Fig. 3. In every spectrum, desorptions of $\mathrm{D}_{2}, \mathrm{HD}, \mathrm{HDO}$ and $\mathrm{D}_{2} \mathrm{O}$ were observed, and the desorption amount of $\mathrm{D}_{2}$ was largest. The Ti had a sharp desorption peak at $650 \mathrm{~K}$. Titanium forms a stable hydride, so that this peak is due to de-trappings of deuterium from Ti-D bond. The amount of deuterium retained in Ti was also large, $3.3 \times 10^{17} \mathrm{D} / \mathrm{cm}^{2}$. In the spectrum of $\mathrm{B}$, two desorption peaks appeared at about $500 \mathrm{~K}$ and $750 \mathrm{~K}$. The lower and higher peaks are due to the desorptions of deuteriums trapped in forms of B-D-B and B-D [10], respectively. The amount of deuterium retained in $\mathrm{B}$ was smaller than that in $\mathrm{Ti}$. In the spectrum in B-Ti, two desorption peaks appeared at approximately $470 \mathrm{~K}$ and $620 \mathrm{~K}$. The lower and higher temperature peaks are due to the desorptions of deuterium trapped in forms of B-D-B and Ti-D, respectively. The peak due to desorption of deuterium trapped in form of B-D was not observed.

In order to understand the desorption behavior of deuterium in $\mathrm{B}-\mathrm{Ti}$, the deuterium ion irradiation was similarly conducted for $\mathrm{TiB}_{2}$. The desorption spectra of deuterium at different ion fluences are shown in Fig. 4. There were two desorption peaks. One was at about $620 \mathrm{~K}$ due to the de-trapping from Ti-D bond and the other was at approximately $750 \mathrm{~K}$ due to the de-trapping from B-D bond. The peak intensity at $620 \mathrm{~K}$ was larger than that at $750 \mathrm{~K}$, which indicates that the deuterium is more trapped by titanium compared with the boron. In these spectra, no peak at approximately $500 \mathrm{~K}$ was observed. Figure 5 shows the comparison between desorption spectra of $\mathrm{B}-\mathrm{Ti}$ and $\mathrm{TiB}_{2}$, when the ion fluence was the same, $5 \times 10^{18} \mathrm{D} / \mathrm{cm}^{2}$. These results suggest that only B-D and Ti-D bonds are produced in $\mathrm{TiB}_{2}$ but $\mathrm{B}-\mathrm{D}-\mathrm{B}$ bond is not produced.

\section{(3) Crystal Structures and Chemical Binding States in B-Ti and $\mathrm{TiB}_{2}$}

The crystal structures of $\mathrm{B}-\mathrm{Ti}$ and $\mathrm{TiB}_{2}$ were examined by XRD. Figure 6 shows $\mathrm{X}$-ray diffraction spectra. The $\mathrm{B}$-Ti had no dominant peaks, although the $\mathrm{TiB}_{2}$ had several sharp peaks of $\mathrm{TiB}_{2}$. The chemical binding states in $\mathrm{B}-\mathrm{Ti}$ and $\mathrm{TiB}_{2}$ were examined by using XPS. The spectra of $\mathrm{B}_{1 \mathrm{~s}}$ are shown in Fig. 7. The $\mathrm{TiB}_{2}$ had a sharp peak at $\mathrm{TiB}_{2}$. The $\mathrm{B}-\mathrm{Ti}$ had a board peak between $\mathrm{B}-\mathrm{B}$ and $\mathrm{TiB}_{2}$. Namely, the titanium 
and the boron is not sufficiently bonded in B-Ti, although the titanium and the boron in $\mathrm{TiB}_{2}$ is significantly bonded. These results indicate that there is a lot of un-bonded boron in B-Ti since the structure in both XRD and XPS is more amorphous compared with $\mathrm{TiB}_{2}$. The structure in $\mathrm{B}-\mathrm{Ti}$ becomes more amorphous during the energetic deuterium ion irradiation. Thus, the bonding of B-D-B is easily produced. This is a reason for the appearance of deuterium desorption in the low temperature regime in B-Ti.

The difference of desorption behavior in these materials is clearly seen if the desorption rates are plotted in the same figure. Figure 8 shows desorption rates of deuterium for $\mathrm{Ti}, \mathrm{B}, \mathrm{B}-\mathrm{Ti}$ and $\mathrm{TiB}_{2}$. In this figure, the scale of desorption rate for $\mathrm{Ti}$ is 20 times reduced. The amount of deuterium retained in B-Ti was 3 times and twice smaller than those in $\mathrm{Ti}$ and $\mathrm{B}$, respectively, and comparable with that of $\mathrm{TiB}_{2}$. The higher peak temperature of deuterium desorption in B-Ti was $620 \mathrm{~K}$, comparable with that in $\mathrm{Ti}$ and lower peak temperature in $\mathrm{TiB}_{2}$. The lower peak temperature in $\mathrm{B}$ - $\mathrm{Ti}$ was about $500 \mathrm{~K}$, comparable with the lower peak temperature in $\mathrm{B}$. The higher peak temperature at about $750 \mathrm{~K}$ in $\mathrm{TiB}_{2}$ is comparable with that of higher peak in $\mathrm{B}$. The average desorption temperature in $\mathrm{B}-\mathrm{Ti}$ is $70-140 \mathrm{~K}$ lower than that of $\mathrm{B}, \mathrm{Ti}$ and $\mathrm{TiB}_{2}$.

If in the $\mathrm{B}$ - $\mathrm{Ti}$ the deuterium is preferentially trapped by titanium, the desorption peak due to the de-trapping of deuterium from Ti-D bond becomes dominant. In addition, if the titanium is partly bonded with the boron, the number of trapping site in the titanium becomes smaller, resulting a smaller amount of retained deuterium compared with the case of Ti. This may be a reason that the amount of deuterium retained in the $\mathrm{B}$ - $\mathrm{Ti}$ was smallest. In the case of $\mathrm{TiB}_{2}$, un-bonded $\mathrm{B}$ and $\mathrm{Ti}$ are produced only by the energetic deuterium ions. Then, the deuterium is trapped in forms of Ti-D and B-D. This is a reason for that the desorption peaks appear at around 620K and $750 \mathrm{~K}$.

\section{(4) Deuterium Retention in B-Ti after Helium Ion Irradiation}

In fusion devices, wall surfaces are exposed to helium ions during helium glow discharge conditionings and helium ions produced by fusion reactions. In order to simulate the fuel hydrogen retention in B-Ti wall under such the condition, helium ion irradiation was conducted for B-Ti after the deuterium ion irradiation. Several B-Ti samples were newly prepared for this experiment. The deuterium retention and desorption behavior after the helium ion irradiation was investigated.

The deuterium ion irradiation with a fluence of $5 \times 10^{18} \mathrm{D} / \mathrm{cm}^{2}$ was similarly conducted for B-Ti at RT, and after that the irradiations of helium ions with energy of 5 
$\mathrm{keV}$ and fluences of $5 \times 10^{18}$ and $1 \times 10^{19} \mathrm{He} / \mathrm{cm}^{2}$ were conducted in the same ion source. Figure 9 shows thermal desorption spectra before helium ion irradiation (Fig. 9(a)), and after helium ion irradiations (Figs. 9(b) and (c)). The desorption rates of HD, $\mathrm{HDO}$ and $\mathrm{D}_{2} \mathrm{O}$ are shown only in Fig. 9(a). The impurity desorption behavior was similar in the cases of Figs.9 (b) and (c). The desorption spectrum before helium ion irradiation is slightly different with that of B-Ti in Fig. 3. The peak intensity due to B-D-B bond in Fig. 9 (a) is smaller than that in Fig. 3. This tendency appears if the boron concentration is relatively low. The spectrum significantly changed after the helium ion irradiation as seen in Figs. 9(b) and (c). The amount of retained deuterium decreased with the increase of helium ion fluence. The peak intensity also shifted to the low temperature regime. The peak intensity due to the Ti-D bond decreased and the peak intensity due to the B-D-B bond relatively increased. This result suggests that the deuterium is more trapped in form of B-D-B since the boron becomes more amorphous by helium ion irradiation. This result is important for the wall conditionings. Namely, the wall baking temperature required for reduction of fuel hydrogen retention becomes significantly low for B-Ti after helium ion irradiation. The baking temperature with only $600 \mathrm{~K}$ can reduce the deuterium retention very well if the wall is irradiated by the similar helium ion bombardment.

\section{Conclusion}

Boron-titanium (B-Ti) was prepared by electron beam evaporations for $\mathrm{Ti}$ and $\mathrm{B}$ followed by annealing. The boron-titanium was irradiated by deuterium ions with an energy of $1.7 \mathrm{keV}$ at RT. Similar experiments were conducted for $\mathrm{Ti}, \mathrm{B}$ and $\mathrm{TiB}_{2}$. The amount of retained deuterium in B-Ti was several times smaller than that in B or Ti, and comparable with that in $\mathrm{TiB}_{2}$.

The desorption temperatures of deuterium in B-Ti were $470 \mathrm{~K}$ and $620 \mathrm{~K}$. The lower and higher temperatures correspond to the lower desorption temperature of $\mathrm{B}$ and desorption temperature of $\mathrm{Ti}$, respectively. The desorption peak at the higher temperature of B was not observed in B-Ti under the present irradiation condition. The dangling bonds of $\mathrm{B}$ and $\mathrm{Ti}$ exists in $\mathrm{B}-\mathrm{Ti}$ and these states are enhanced by the energetic deuterium ion irradiation, so that the deuterium might have been trapped in forms of B-D-B and Ti-D. In $\mathrm{TiB}_{2}$, the desorptions due to Ti-D and higher peak in B appeared. In the crystallized $\mathrm{TiB}_{2}$, dangling bond of $\mathrm{B}$ after the energetic deuterium ion irradiation is not enough to produce B-D-B bond, so that the peak due to B-D-B might not have appeared. The desorption temperature in $\mathrm{B}-\mathrm{Ti}$ was significantly lower than that of $\mathrm{B}, \mathrm{Ti}$ and $\mathrm{TiB}_{2}$. This reason is that $\mathrm{B}-\mathrm{D}-\mathrm{B}$ bonds are more produced in $\mathrm{B}-\mathrm{Ti}$. The number of 
B-D-B bond was furthermore increased by the energetic helium ion irradiation, so that the desorption temperature shifted to the temperature of deuterium de-trapping from B-D-B. In addition, the amount of retained deuterium was significantly reduced by the helium ion irradiation.

The above results suggest that the use of $\mathrm{B}$-Ti significantly contributes to the reductions of fuel hydrogen recycling and in-vessel tritium inventory. In DT burning devices, the baking temperature for control of fuel hydrogen recycling can be low, approximately $600 \mathrm{~K}$, and the in-vessel tritium inventory at wall surfaces can be also significantly reduced if B-Ti is employed. Finally it is noted that B-Ti on the first wall is easily produced if both boronization and titanium flash are applied.

\section{Acknowledgements}

This work was conducted as the Collaboration Research Program for Large Helical Device (NIFS04KOBS005) in National Institute for Fusion Science, and partly supported by the JSPS-CAS Core University Program in the field of Plasma and Nuclear Fusion.

\section{References}

[1] T. Hino, L. Rovner and T. Ohkawa, Hydrogen emitting limiter and its approach to impurity control, General Atomic Company Report, GA-A16251, 1981.

[2] J. Winter, Boronization in TEXTOR, J. Nucl. Mater. 162-164 713, 1989.

[3] H. G. Esser, A. I. Lyssoivan, M. Freisinger et al, Deposition of a-C/B:D layers by ICRF-wall conditioning in TEXTOR-94, J. Nucl. Mater., 266-269 (1999)240.

[4] K. Tsuzuki, M. Natsir, N. Inoue, A. Sagara, N. Noda et al Hydrogen absorption behavior into boron films by glow discharge in hydrogen and helium, J. Nucl. Mater., 241-243 (1997),1055.

[5] T. Hino, T. Mochizuki, Y. Hirohata, K. Tsuzuki, N. Inoue et al, Oxygen gettering properties of boron film produced by diborane dc glow discharge, J. Nucl. Mater., 248 (1997)38.

[6] O. Motojima, H. Yamada, A. Komori, Y. Watanabe, T. Mutoh et al, Review on the progress of the LHD experiment, Fusion Sci. and Technol., 46 (2004 91.

[7] H. Eiki, H. Yanagihara, Y. Hirohata, T. Hino, K. Tsuzuki et al, Hydrogen retention properties of boron film with surface oxidation (in Japanese), J. Vac. Soc., Jpn., 41 (1998)119.

[8] T. Hino, Y. Hashiba, Y. Yamauchi, Y. Hirohata, K. Nishimura et al, Deuterium retention and desorption behavior of boron-titanium as first wall 
material of fusion experimental device, Fusion Eng. and Design, 81 (2006)127.

[9] Y. Yamauchi, T. Hino, K. Koyama, Y. Hirohata, T. Yamashina, Hydrogen retention properties of low Z and high Z materials, J. Nucl. Mater., 241-243 (1997)1016.

[10] For example, see Y. Oya, H. Kodama, M. Oyaidzu, Y. Moromoto, M. Matsuyama, A. Sagara et al, Implanted hydrogen isotope and chemical behavior in boron thin films for wall conditioning, J. Nucl.Mater., 329-333 (2004)870.

[11] N. Kikuchi, Deuterium retention and desorption behavior of boron titanium (in Japanese), Thesis for Mater Degree, Hokkaido University, 2005

\section{Figure captions}

Figure 1. Depth profile of atomic composition for $\mathrm{TiB}_{2}$.

Figure 2. Depth profiles of atomic composition for B (a), Ti (b), B-Ti (c) and B-Ti annealed (d).

Figure 3. Thermal desorption spectra of deuterium in B, Ti and B-Ti when deuterium ion fluence was $5 \times 10^{18} \mathrm{D} / \mathrm{cm}^{2}$.

Figure 4. Thermal desorption spectra of deuterium at different ion fluences in $\mathrm{TiB}_{2}$.

Figure 5. Thermal desorption spectra of deuterium in $\mathrm{TiB}_{2}$ and $\mathrm{B}-\mathrm{Ti}$ when deuterium ion fluence was $5 \times 10^{18} \mathrm{D} / \mathrm{cm}^{2}$.

Figure 6. XRD patterns in $\mathrm{TiB}_{2}$ and $\mathrm{B}-\mathrm{Ti}$.

Figure 7. XPS spectra of $\mathrm{B}_{1 \mathrm{~s}}$ in $\mathrm{TiB}_{2}$ and. $\mathrm{B}-\mathrm{Ti}$

Figure 8. Desorption spectra of deuterium in $\mathrm{TiB}_{2}, \mathrm{~B}-\mathrm{Ti}, \mathrm{B}$ and $\mathrm{Ti}$ when the ion fluence was $5 \times 10^{18} \mathrm{D} / \mathrm{cm}^{2}$.

Figure 9. Deuterium desorption spectra in B-Ti before helium ion irradiation (a), and after helium ion irradiations, $5 \times 10^{18} \mathrm{He} / \mathrm{cm}^{2}$ (b) and $1 \times 10^{19} \mathrm{He} / \mathrm{cm}^{2}$ (c). 


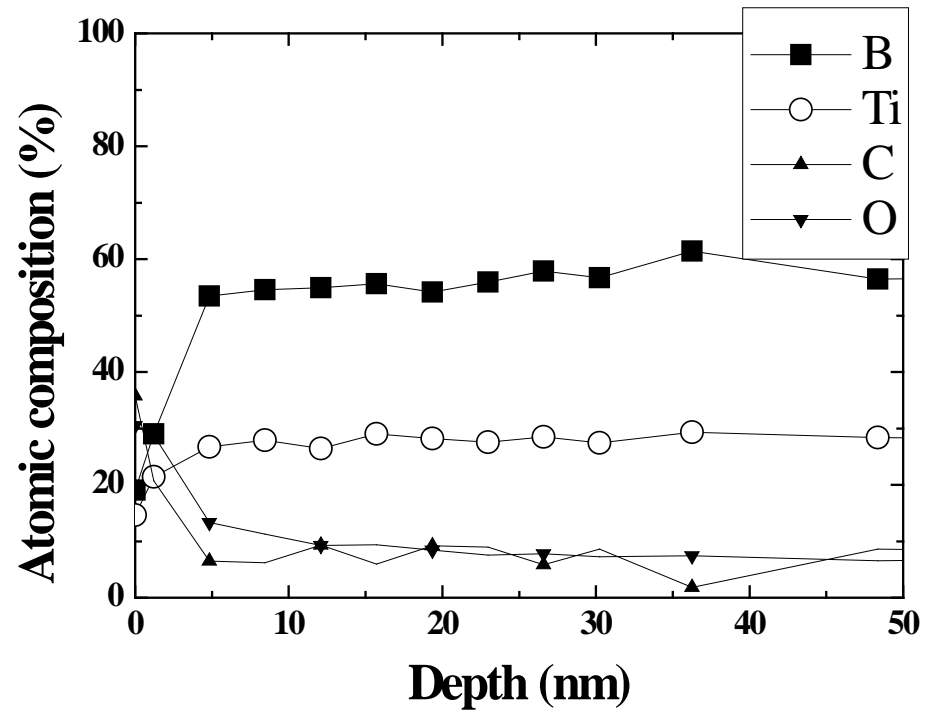

Fig. 1 
(a) $\mathrm{B}$

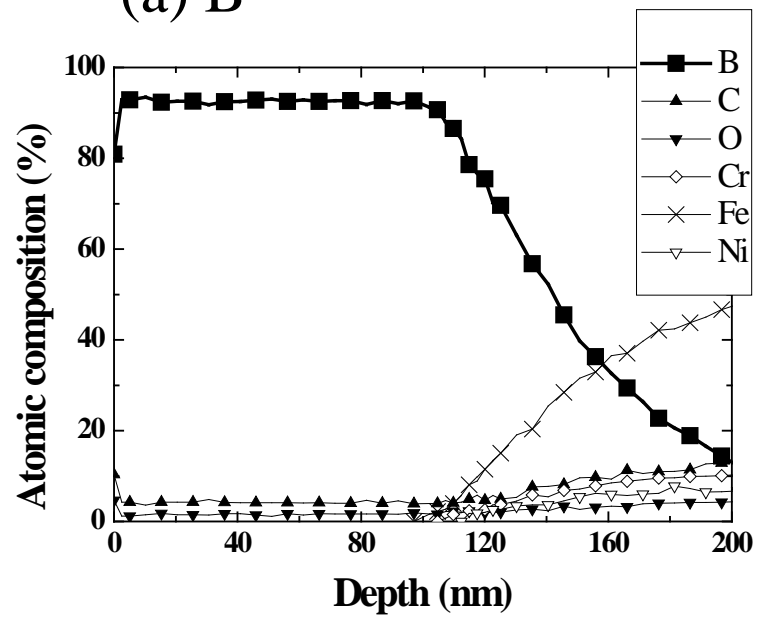

(c) $\mathrm{B}-\mathrm{Ti}$

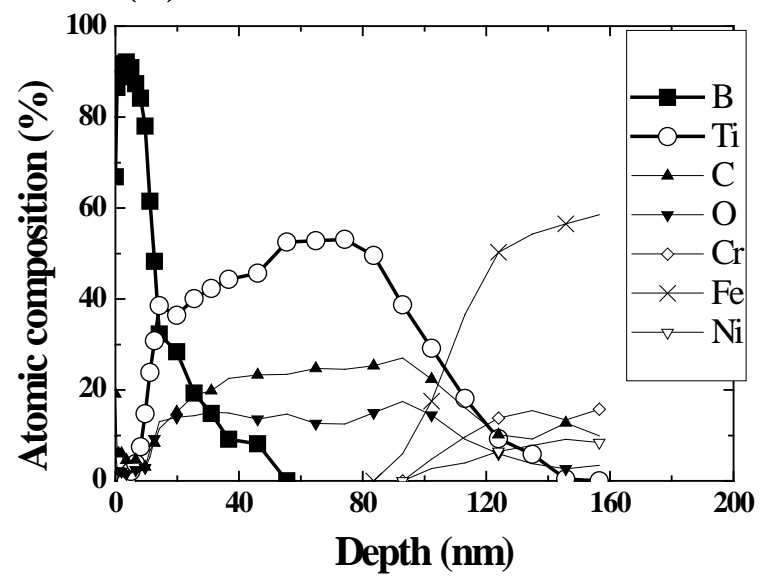

(b) $\mathrm{Ti}$

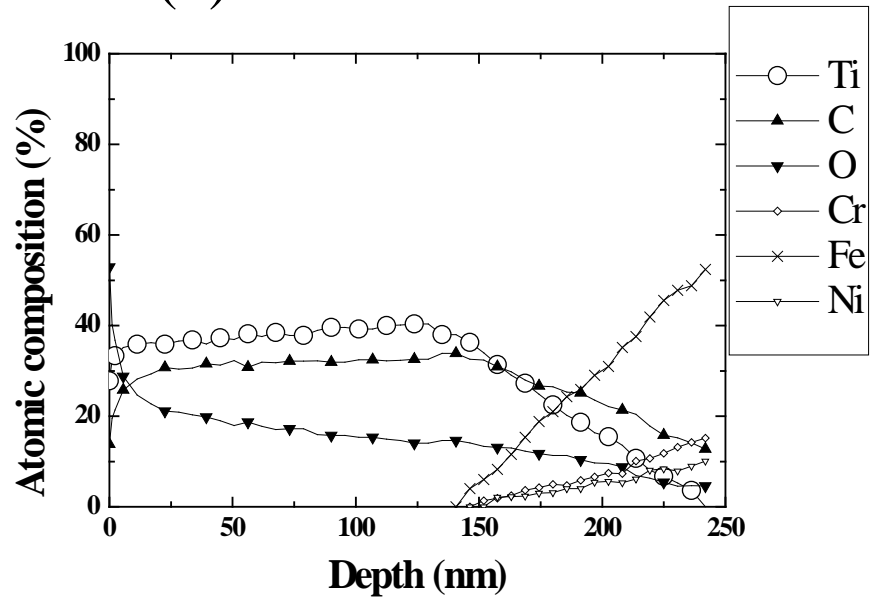

(d) B-Ti Annealed

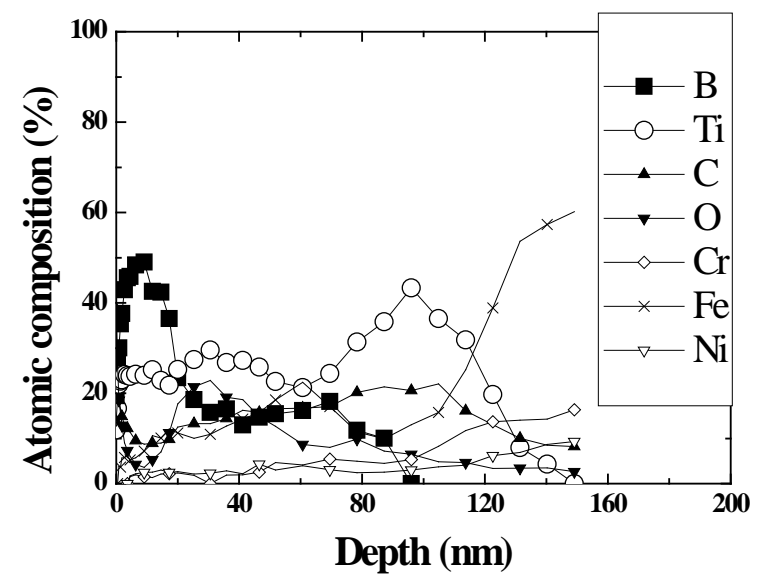

Fig. 2 


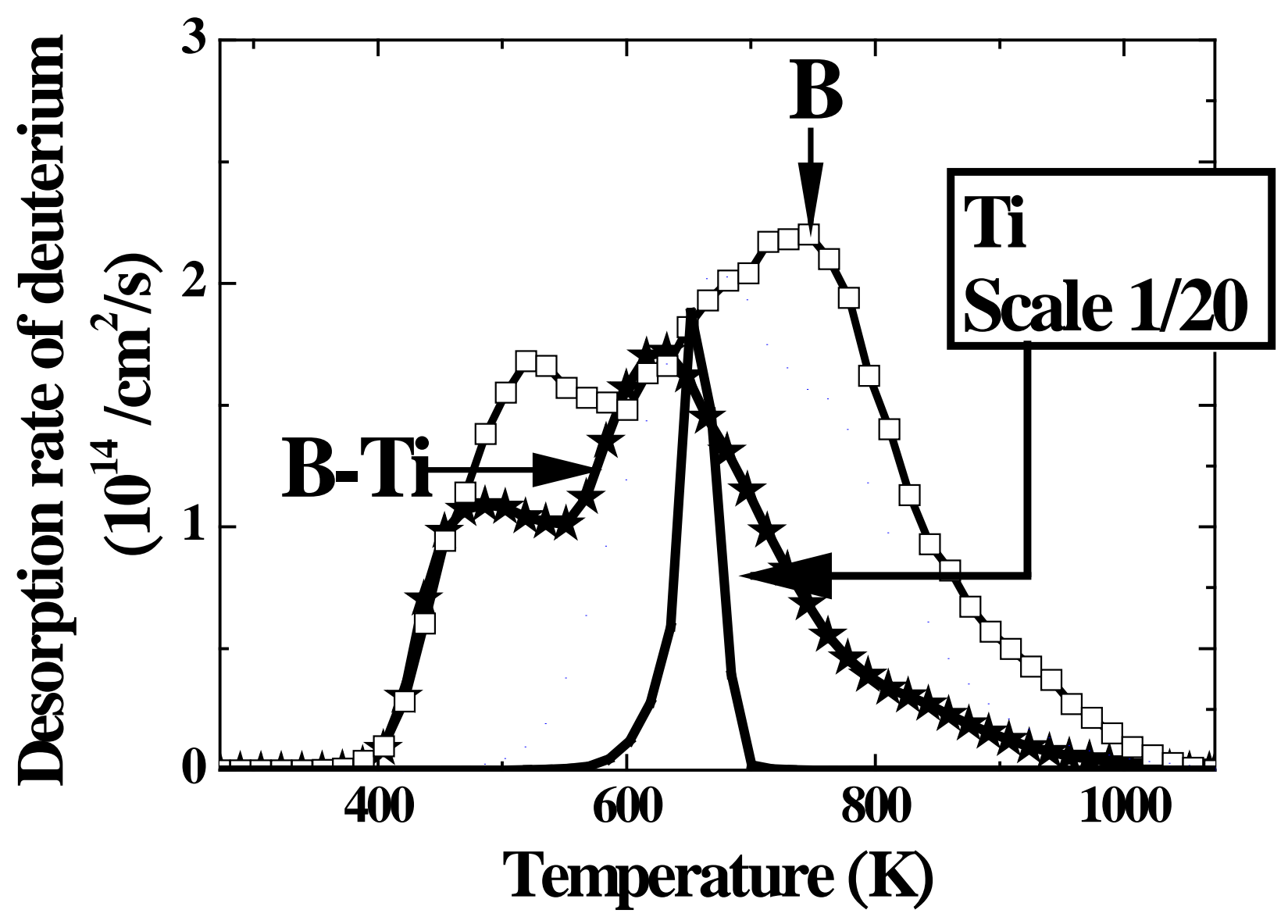

Fig. 3 


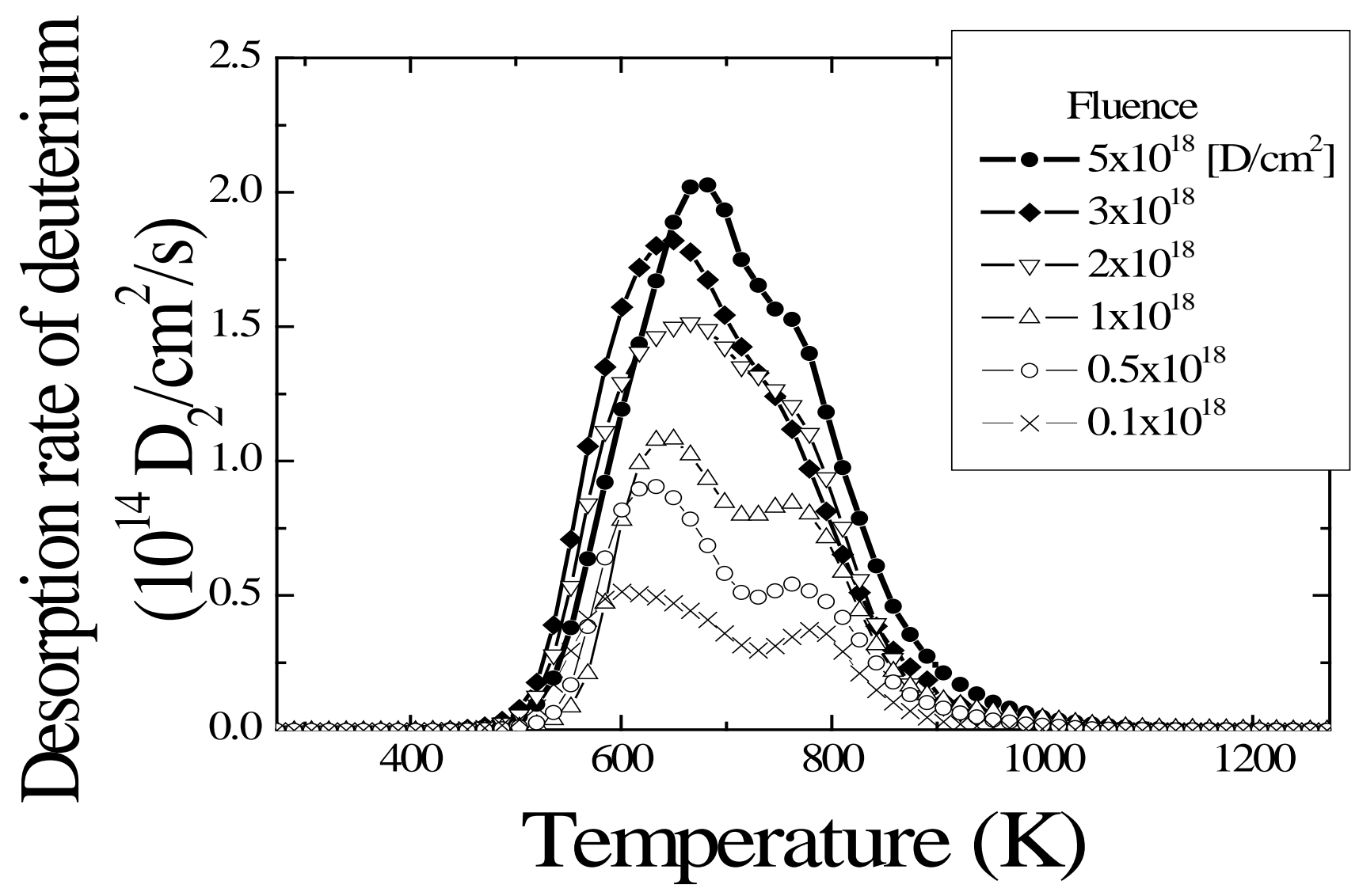

Fig. 4 


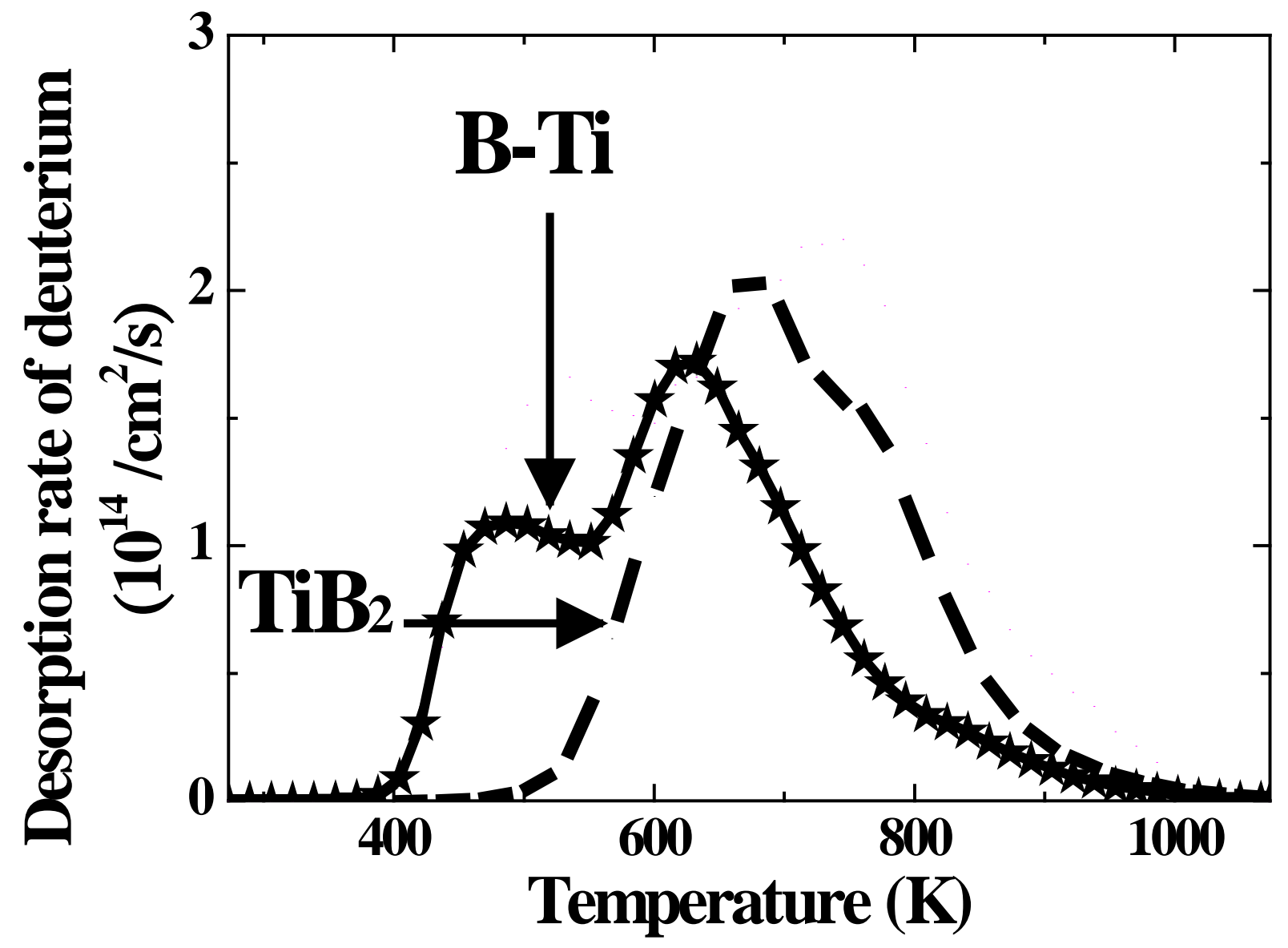

Fig. 5 

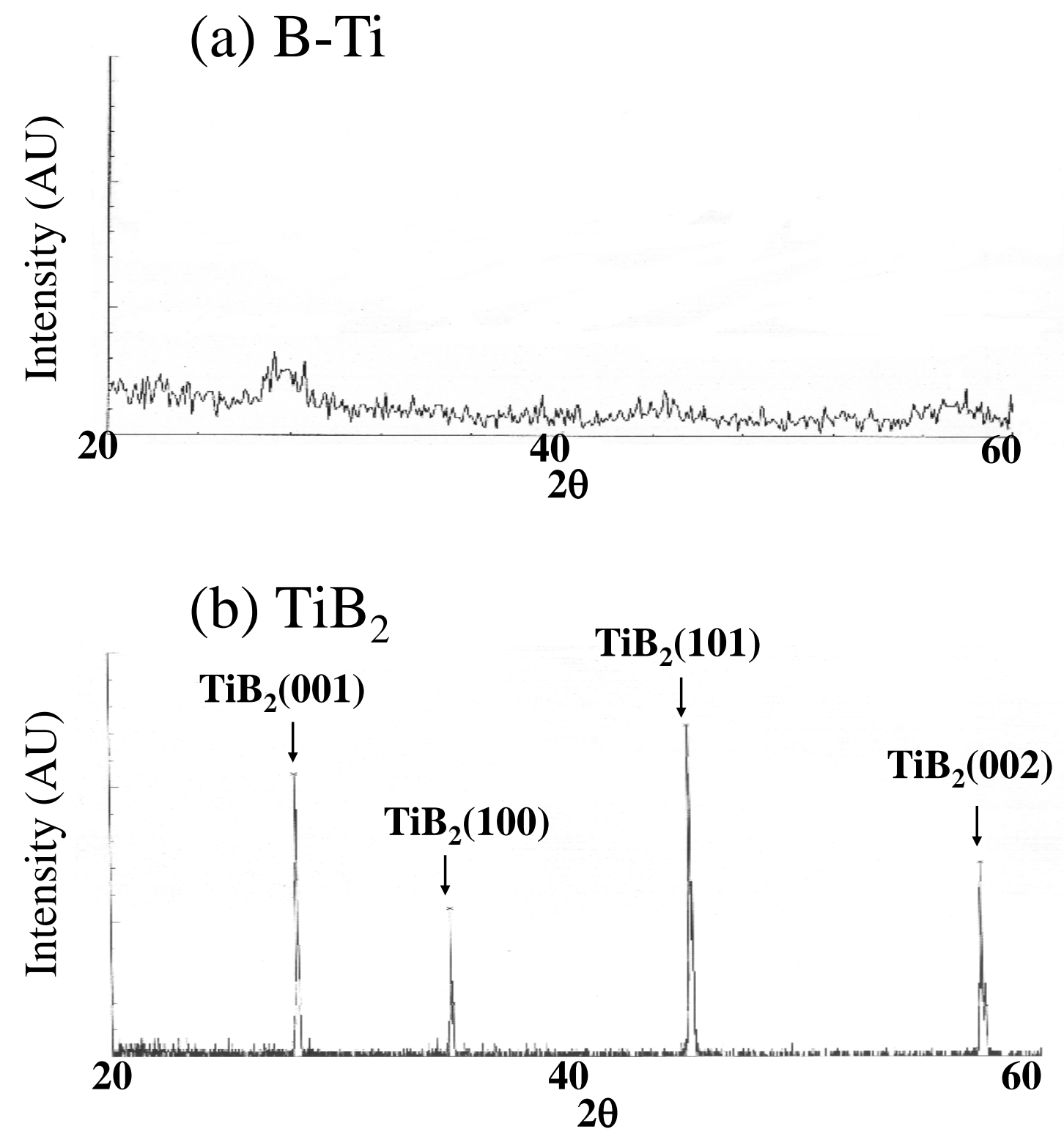

Fig. 6 
(a) $\mathrm{B}-\mathrm{Ti}$

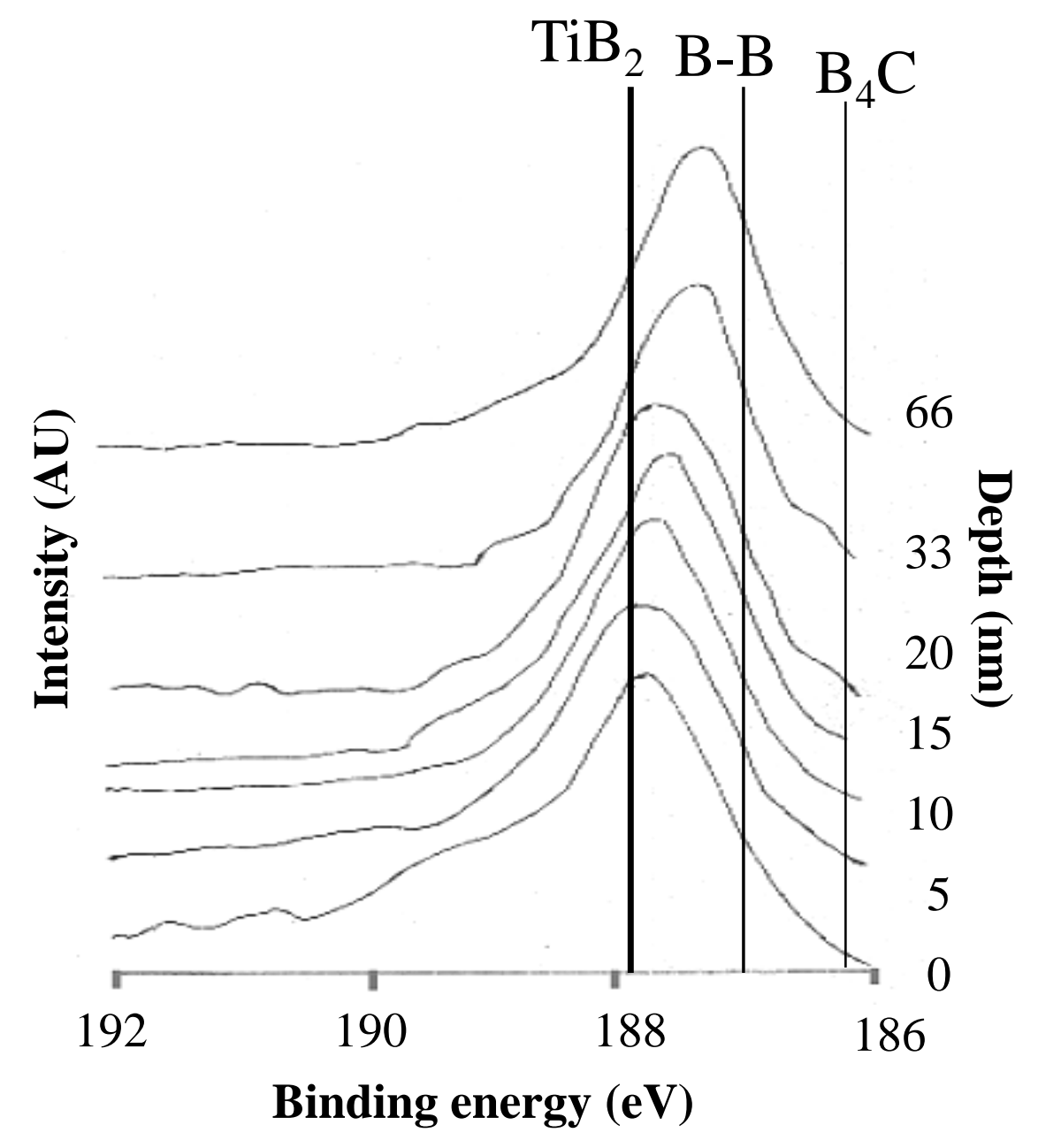

(b) $\mathrm{TiB}_{2} \quad \mathrm{TiB}_{2} \mathrm{~B}-\mathrm{B} \mathrm{B}_{4} \mathrm{C}$

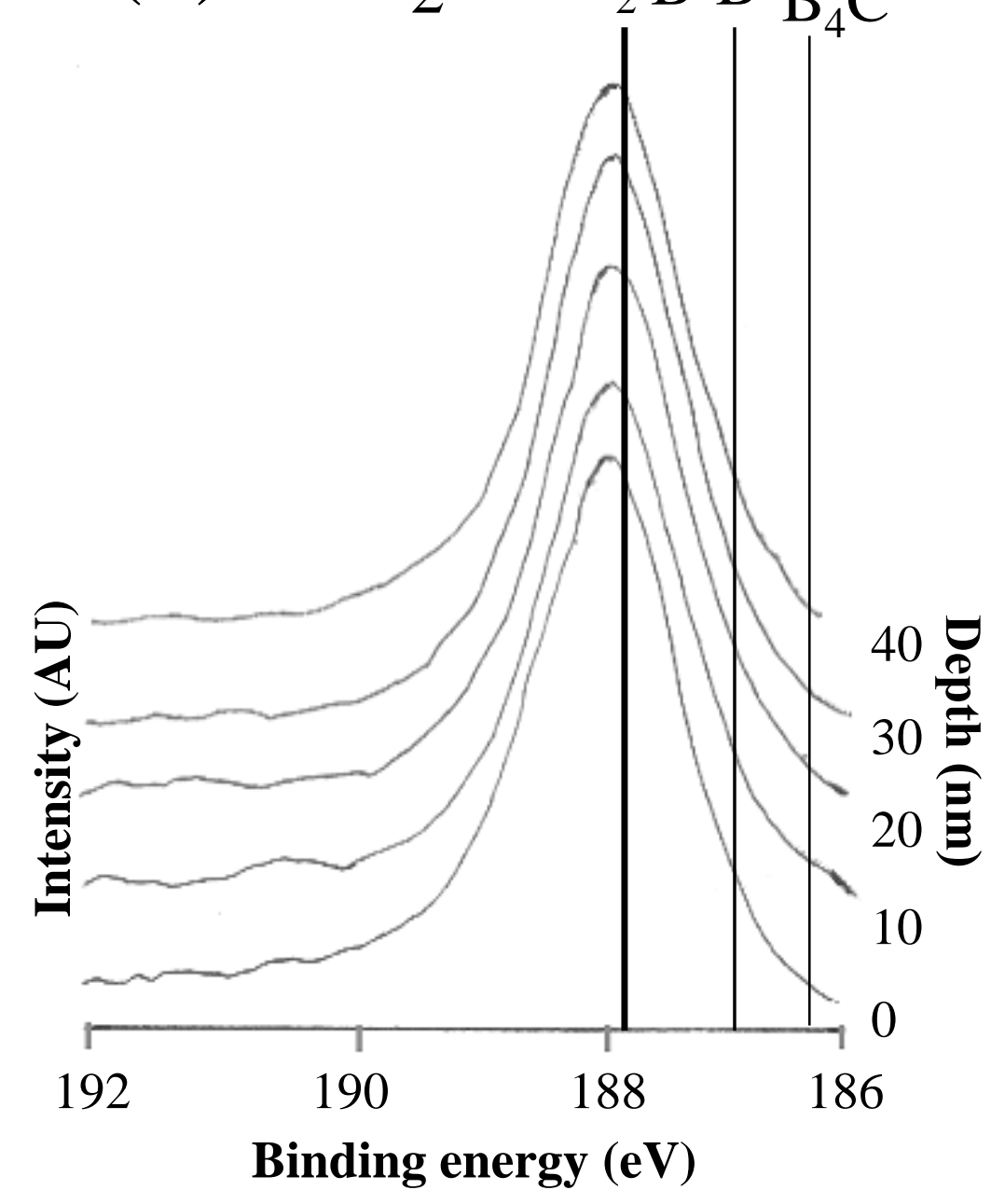

Fig. 7 


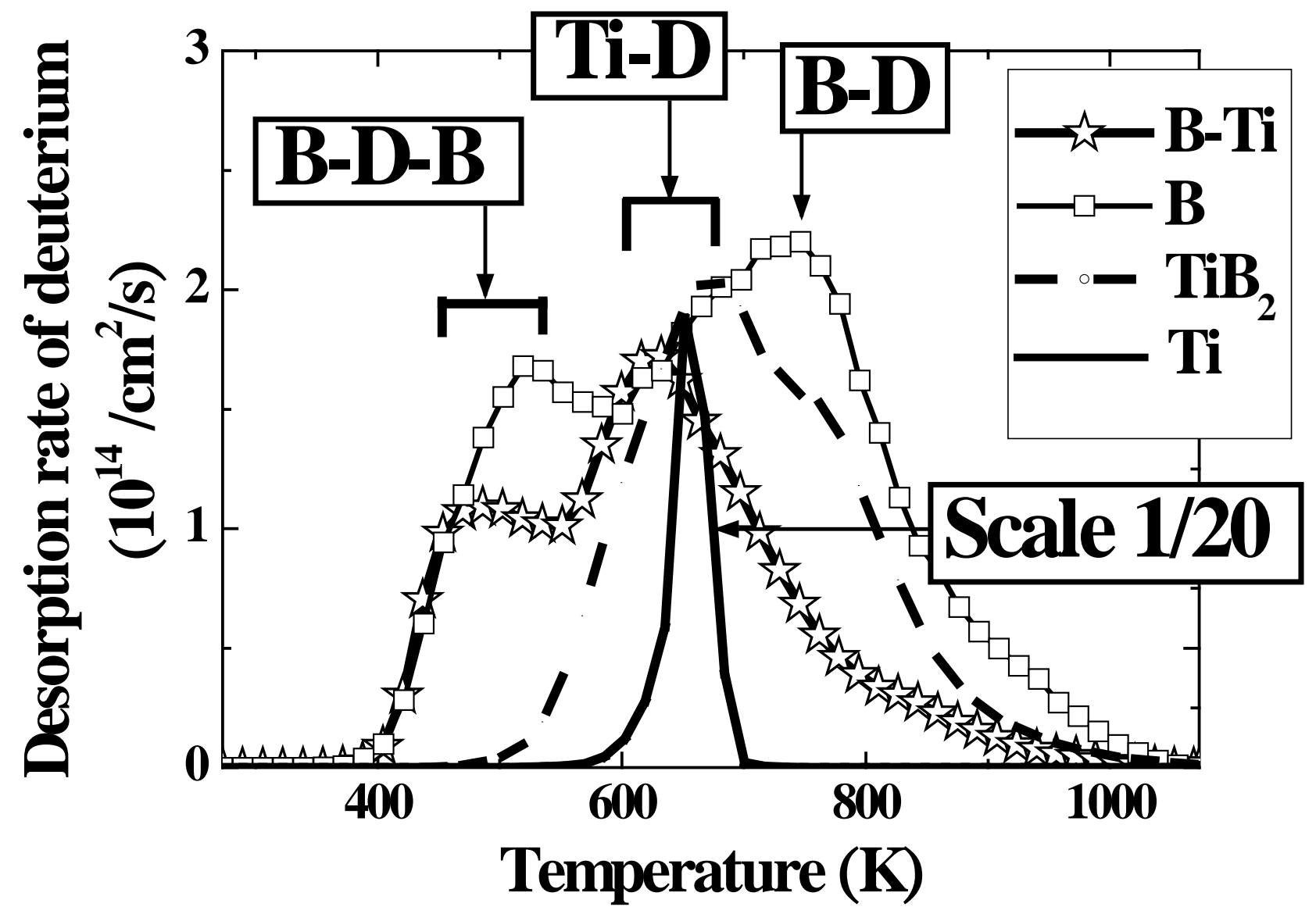

Fig. 8 
(a)

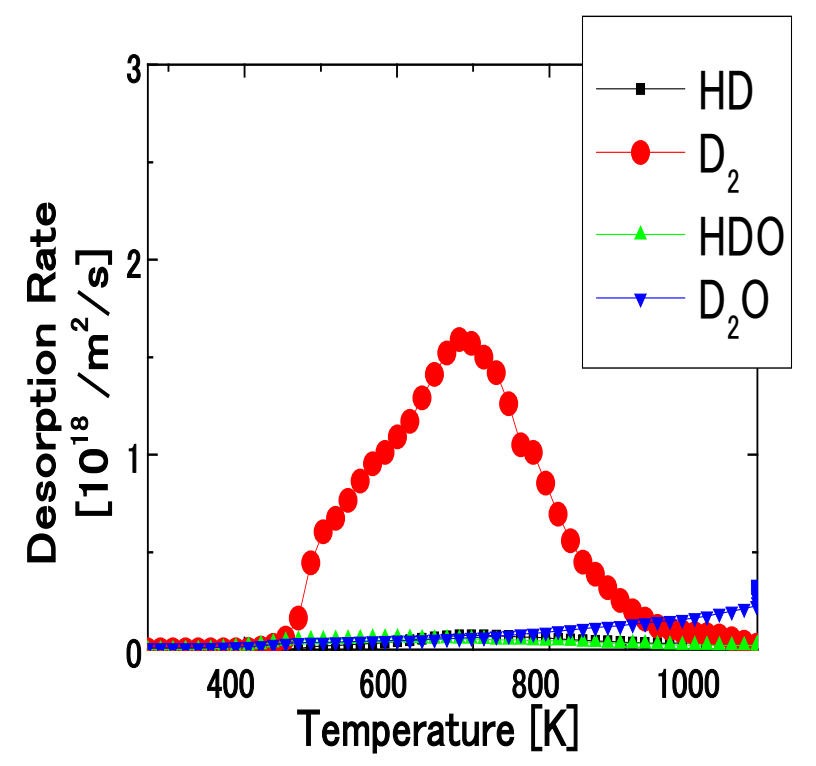

(b)

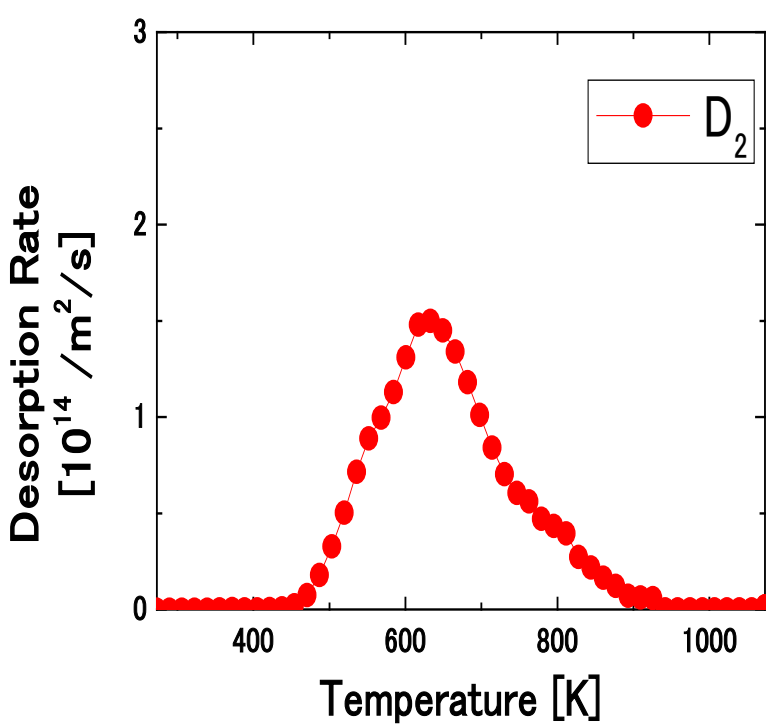

(c)

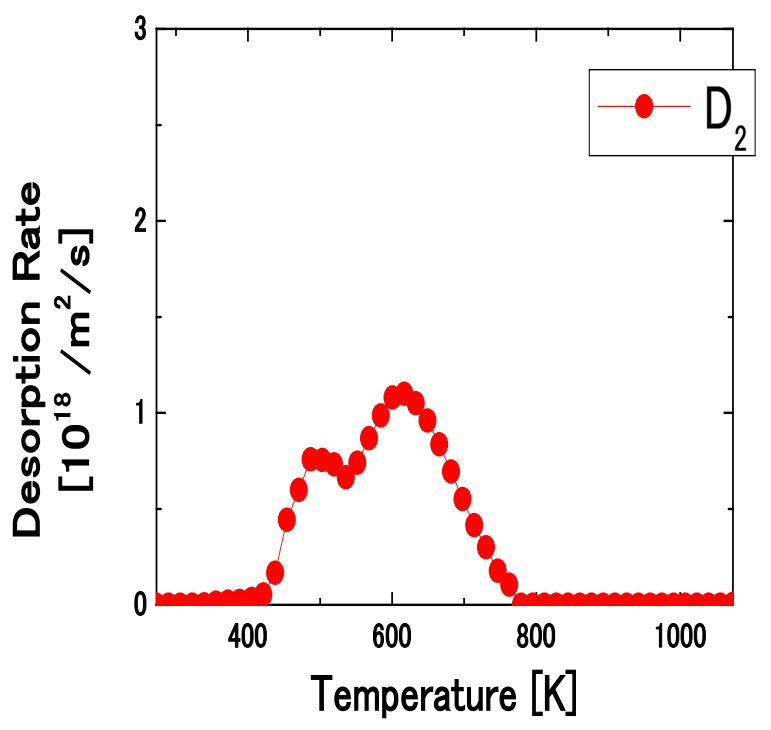

Fig. 9 